\title{
Proposing Faculty Performance Monitoring Scale (FPMS) as an Application of Ambient Intelligence
}

\author{
Raj Seth \\ Department of Applied Sciences \\ Sri Sai University, Palampur (HP), India
}

\author{
Rimmy Chuchra \\ Department of Computer Science \& Engg. \\ Sri Sai College of \\ Engg and Technology, \\ Manawala (Amritsar), Punjab
}

\begin{abstract}
Ambient Intelligence in the modern era of research and innovations is an active field that uses various embedded computing devices for providing different types of interaction with environment. This paper describes a new methodology "Faculty Performance Monitoring Scale" abbreviated as "FPMS" aiming to improve the overall quality of existing education system utilizing an application of ambient intelligence. As designed, the methodology elaborates the mutual interaction among humans and service robotics having master-slave relationship in which humans act as a master and service robotics act as a slave. Human utilizes interface embedded in service robotics for giving instruction and service robotics will respond according to the instruction given by the master. The primary duty of service robotics is to store and monitor the faculty members at the time of lecture delivery and calculate their performance on the basis of certain parameters as considered in FPMS. The benefit to utilize this designed methodology is to reduce conflicts among faculty based upon biases' and appreciation will be given on the basis of feedback from FPMS. An appropriate collaboration between human and service robotics leads to achieve a joint action and provides a mechanism of active team participation utilizing a more natural form of interactions. The proposed architecture design has been compared with the current education system and may be followed by the educational institutes for maintaining efficiency as the case thereof.
\end{abstract}

\section{Keywords}

Ambient Intelligence, Service Robotics, Sensors, micro-chip, performance, Education system, Faculty.

\section{INTRODUCTION}

Ambient intelligence is a multi-disciplinary field [15] [24] aiming to provide interaction [5] with physical environment by utilizing various network computing devices as sensors, actuators and embedded systems etc. The significance for developing separate combinations of separate devices is to just change the behavior of physical_environment to digital environment describing the dynamic nature of AI [8]. This dynamic behavior helps to provide a better way of interaction with physical world and covers a wide area of applications in multi-disciplinary field. Some are listed below:

- It not only helps to capture data from the real/physical world but also helps to capture data through processing by utilizing some certain shortcuts methods [25].

- Gives a major opportunity that is "Learning from the environment". In this case, it gives chance to people think differently like Driverless cars manufactured by Google [39].
- Provides an easy platform that helps to detect the presence of people in the room, their needs as well as intensions that are free from the manual control of their surroundings [16].

- Most importantly, it is quite near to eliminating constraints over input applied. In this paper authors considered an example of service robotics having intelligent behavior in dynamic environment that can accept input in any form viz. voice and gesture/posture depending on the type of programming embedded into it such as sensing, perception, knowledge presentation action, planning and its execution. Each function may deal autonomously [11] [8].

- Most commonly, this method is followed by computer professionals using the application of service robotics whose function is to store all the data on sensor nodes and after that operations are applied according to present environment considerations and can be further tested on different platforms such as amazon EC2 Cloud [12][19].

- Provides technology and intelligence collectively by simply packing into a software that can be shown in fig.1:

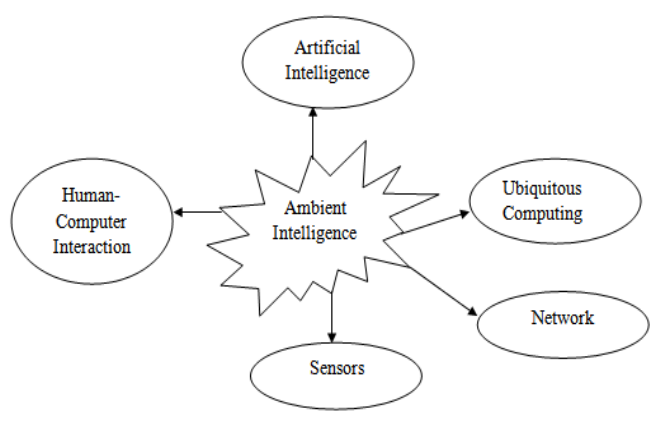

Fig.1: Ambient Intelligence Requires (Technology + Intelligence): Put Into Software Collectively [22].

The main focus of different ambient intelligent applications are only on predicting, planning and managing physical objects that exists in real world and during interaction with separate objects, they must show their individual behavior along with its psychological and social dimensions [6]. As scientists said this type of technology is actually a vision of tomorrow [36] because it behaves intelligently in physical environment [33] \& shows its active participation with humans \& machines that displays their adaptive behavior for providing different type of services [36] [37] in future. As an 
example, a variety of consumer based applications [26] that are listed as follows:

- For pollution Monitoring.

- Traffic management.

- $\quad$ Emergency Response. [25][35].

While implementing consumer based applications using ambient intelligence, researchers noticed that it gives several opportunities how people become a good decision maker in their practical life that subsequently helps to enhance_overall quality of life[26][8][29][20]. In short, this field has long term potential to create several different opportunities for people [27] that shapes in the form of "invisible vision for tomorrow" [23] [11]. Sometimes professionals also called "Disappearing Computing [11][28][38] because it uses an optimal use of input [17] with a short range of network device whose main function is to provide an easy method for communication by utilizing different natural interaction methods and mechanisms. In this way, it also helps to enrich human lives while utilizing intelligent or dynamic environment for performing daily life activities [5]. As researchers did experiment on null input from the environment and guide users how to analyze null input on different types of interactions modes [30] by applying several methods and algorithms that are considered in the terms of invisible interactions [32]. Such type of interactions plays a vital role especially in global computing environment [31. As an example, user's uses mobile phone having sensors may have different feature/function for different model [16] that depends on the type of material at the time of manufacturing. In short, according to researchers, the different methods adopted by the users for input collection may change the user experience [30] with the support of intuitive user interfaces [9] where the main building block of intuitive interface is "checking dynamic resource efficiency" during natural way of interaction [4] with physical world [7]. In this way, this technology plays a vital role for enriching our environment and provides smart living by implementing some certain set of standards [13] [14].

In this paper, authors' designed a methodology named "FPMS" (Faculty Performance Monitoring Scale) that helps to improve overall quality of existing education system using an application of ambient intelligence. This new designed methodology also describes the active participation among humans and service robotics during performing any task and may be shown as in fig. 2 :

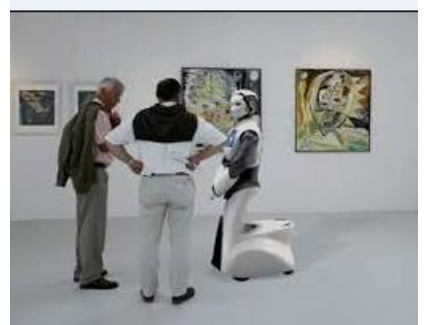

Fig.2: Humans and Service Robotics Took a Joint Action.

Fig. 2 shows that service robotics is completing its tasks in two steps; viz. to store and monitor the continuous exchange of information during lecture delivery by utilizing "FPMS". The duty of Service robotics is to sense the exact location of specific faculty member through sensors at the time of lecture and in addition, it also checks the quality of content that is delivered during lecture by utilizing FPMS. Through this service robotics can easily detect the exact location of that specific faculty member that correspondingly reduces human effort \& saves time during inspection (i.e. surprised checking of lectures). This paper also discusses about the current scenario followed by the universities in education sector that can be shown in fig. 3 :

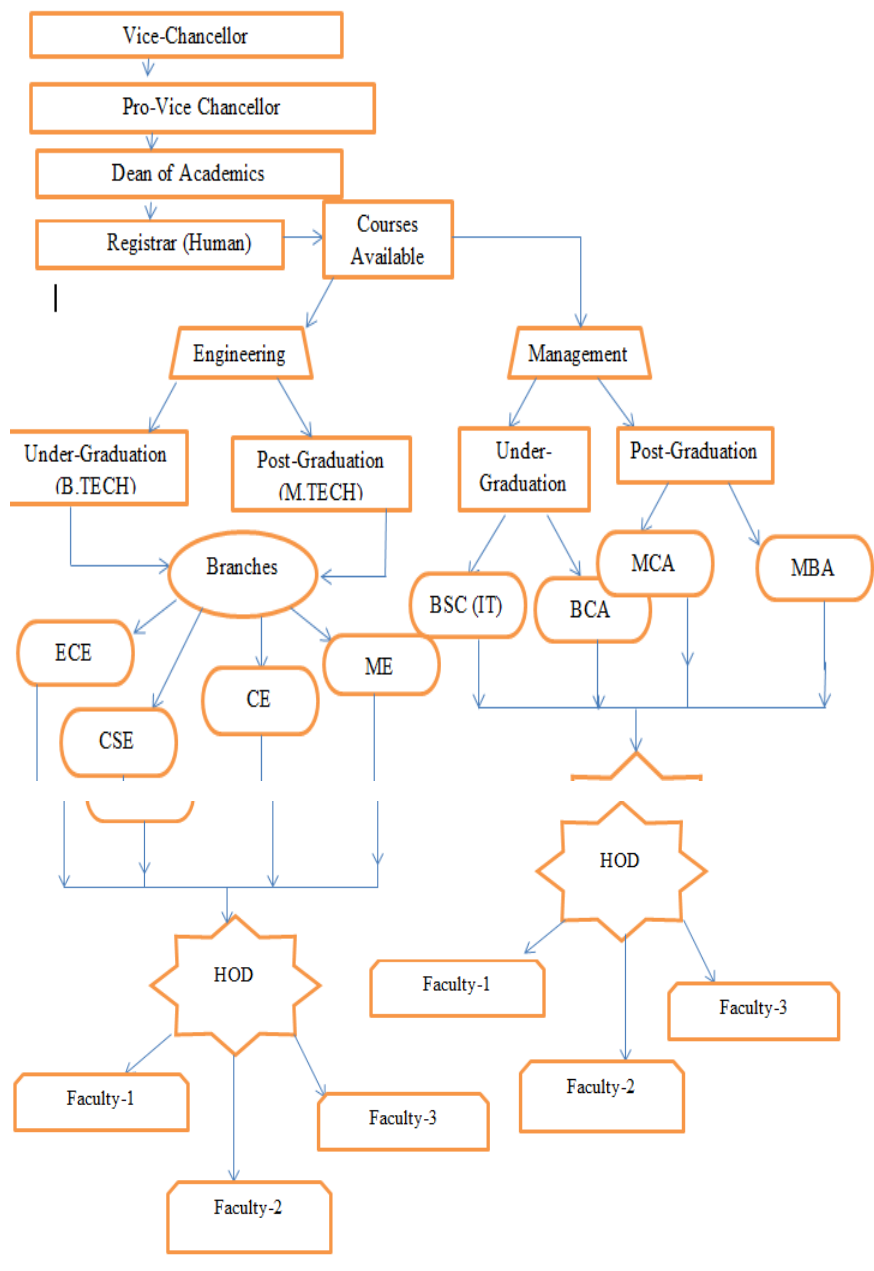

\section{Fig.3: Current Scenario followed by the Education System (Top-to-Bottom Approach).}

The ratio of biasness is greater in existing education system. Therefore for the purpose of reducing conflicts, authors' designed a system that can be shown in fig.4: 


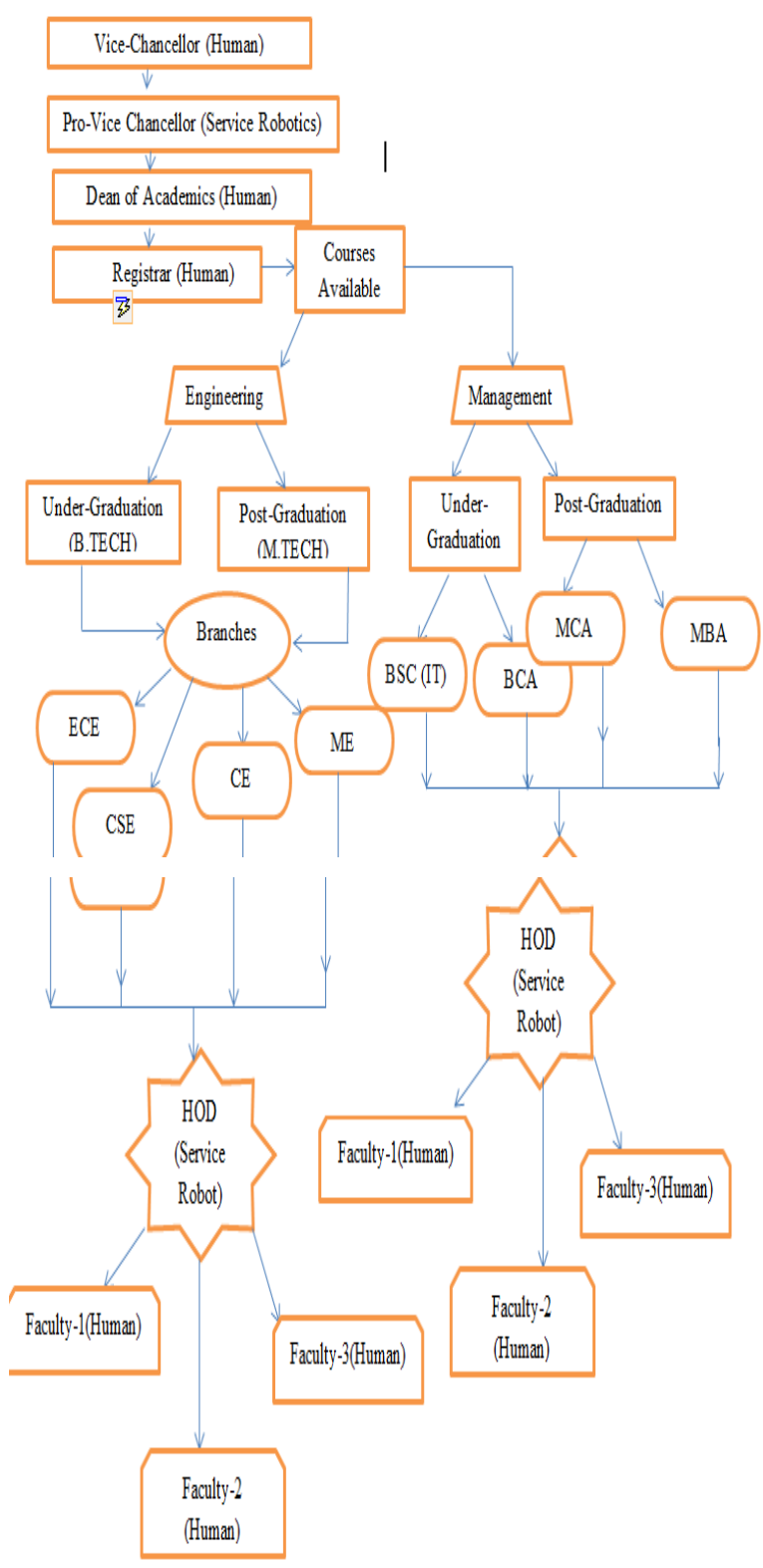

Fig.4: Proposed Scenario followed by the Future Education System (Top-to-Bottom Approach)

The only difference between current and proposed scenario is that heads of the institutes and departments are replaced by Service Robotics. The responsibilities of heads are simply transferred to the Service Robotics. The function of service robotics is only to store and monitor the task of each faculty member and check the performance by analyzing several different parameters that can be shown in table $1 \& 2$ :
Table 1: FPMS: - Faculty Performance Monitoring Scale.

\begin{tabular}{|c|c|c|c|c|c|c|c|c|}
\hline S.NO & Parameters & $\begin{array}{c}\text { Grade } \\
\text { 'A } A^{+}\end{array}$ & $\begin{array}{c}\text { Grade } \\
\text { 'A' }\end{array}$ & $\begin{array}{c}\text { Grade } \\
\text { ' } B \text { ' }\end{array}$ & $\begin{array}{c}\text { Grade } \\
\text { 'C }\end{array}$ & $\begin{array}{c}\text { Grade } \\
\text { 'D' }\end{array}$ & $\begin{array}{c}\text { Grade } \\
\text { ' } E \text { ' }\end{array}$ & $\begin{array}{c}\text { Grade } \\
\text { 'F' }\end{array}$ \\
\hline 1 & $\begin{array}{c}\text { Quality of } \\
\text { Content }\end{array}$ & & & & & & & \\
\hline 2 & $\begin{array}{c}\text { Quantity of } \\
\text { Content }\end{array}$ & & & & & & & \\
\hline 3 & $\begin{array}{c}\text { Problem } \\
\text { Resolving } \\
\text { Round }\end{array}$ & & & & & & & \\
\hline 4 & Test & & & & & & & \\
\hline 5 & Seminars & & & & & & \\
\hline 6 & Quiz & & & & & & & \\
\hline 7 & $\begin{array}{c}\text { Discussion } \\
\text { over Current } \\
\text { Affairs }\end{array}$ & & & & & & & \\
\hline 8 & $\begin{array}{c}\text { Motivation } \\
\text { towards Career }\end{array}$ & & & & & & & \\
\hline 9 & Time_Devision & & & & & & & \\
\hline
\end{tabular}

Table 2: Evaluation of Faculty Members by Using FPMS.

\begin{tabular}{|c|c|c|c|c|c|c|c|c|}
\hline S.N0 & Parameters & $\begin{array}{c}\text { Grade } \\
\text { 'A }\end{array}$ & $\begin{array}{c}\text { Grade } \\
\text { 'A' }\end{array}$ & $\begin{array}{c}\text { Grade } \\
\text { ' } B \text { ' }\end{array}$ & $\begin{array}{c}\text { Grade } \\
\text { 'C' }\end{array}$ & $\begin{array}{c}\text { Grade } \\
\text { 'D' }\end{array}$ & $\begin{array}{c}\text { Grade } \\
\text { 'E' }\end{array}$ & $\begin{array}{c}\text { Grade } \\
\text { 'F' }\end{array}$ \\
\hline 1 & $\begin{array}{c}\text { Quality of } \\
\text { Content }\end{array}$ & $\checkmark$ & & & & & & \\
\hline 2 & $\begin{array}{c}\text { Quantity of } \\
\text { Content }\end{array}$ & & $\checkmark$ & & & & & \\
\hline 3 & $\begin{array}{c}\text { Problem } \\
\text { Resolving } \\
\text { Round }\end{array}$ & & & & & & $\checkmark$ & \\
\hline 4 & Test & & & & $\checkmark$ & & & \\
\hline 5 & Seminars & & & $\checkmark$ & & & & \\
\hline 6 & Quiz & & & & & & & $\checkmark$ \\
\hline 7 & $\begin{array}{c}\text { Discussion } \\
\text { over Current } \\
\text { Affairs }\end{array}$ & & & & & & & \\
\hline 8 & $\begin{array}{c}\text { Motivation } \\
\text { towards Career }\end{array}$ & & & & & & & \\
\hline 9 & Time_Devision & & & & & $\checkmark$ & & \\
\hline
\end{tabular}

Table 3: Grades for FPMS

\begin{tabular}{|c|c|}
\hline $\boldsymbol{A}+$ & $91-100 \%$ \\
\hline $\boldsymbol{A}$ & $81-90 \%$ \\
\hline $\boldsymbol{B}$ & $71-80 \%$ \\
\hline $\boldsymbol{C}$ & $61-70 \%$ \\
\hline $\boldsymbol{D}$ & $51-60 \%$ \\
\hline $\boldsymbol{E}$ & $35-50 \%$ \\
\hline $\boldsymbol{F}$ & Below $35 \%$ \\
\hline
\end{tabular}

In this way, the performance of individual faculty member is calculated. The benefit to utilize FPMS is to improve the overall quality of education system and to achieve major three goals; time saving, security enhancement, and cost saving [25]. All can be discussed below in given list:

- Time Saving: The ambient intelligence follows a feature of ubiquitous computing that indicates presence of a single person at a same time more than one place is possible as behave like virtual users as an example generally, we noticed at present in many institutes HOD perform the task of performance monitoring by giving grading to all faculty members especially through inspection on the time of increments. Here, authors replace HOD with service robotics whose function is only store \& monitor the performance of each faculty member by 
considering some certain parameters that are discussed in table 1 .

- Security: It is must because all the records related with the performance is stored in the service robotics memory by his master who is human by utilizing any programming language like CAD/CAM. He has only authority to lock or unlock the service robotics. Authors noticed quality may be lacking any workplace and therefore to improve the same, an architectural design has been proposed in the education system as shown in fig.5:

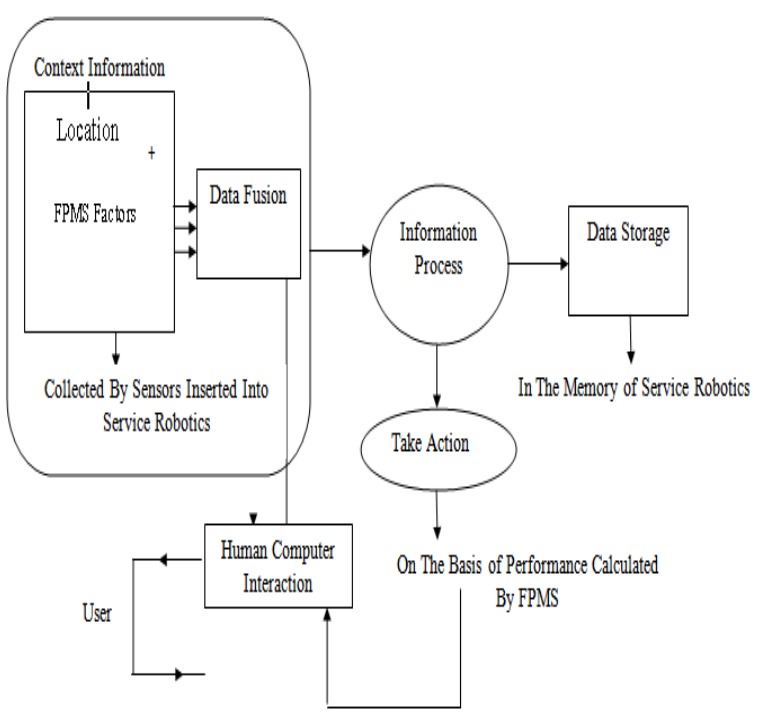

Fig.5: Proposed Architecture for Any University Education System (UES) Using Ambient Intelligence [21].

Using the proposed architecture, once contextual information is collected by sensors, then there is a data fusion process that helps to evaluate output. And this processed information will be used as input for better decision making in future advances [21].

But the most important parameter involving complete functioning that depends on the type of logic implemented in service robotics by the master-human as shown in fig.6:

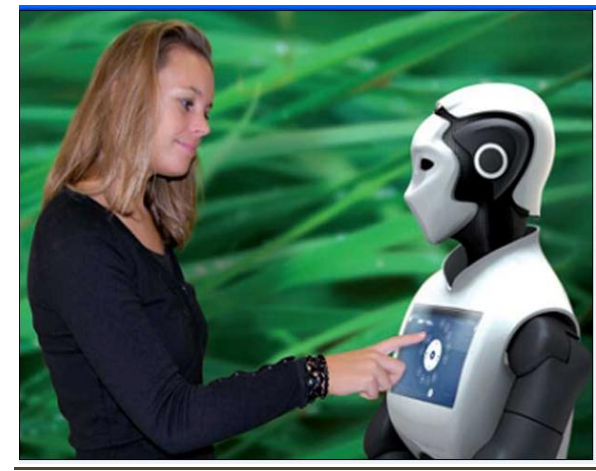

Fig.6: Programming Logic Implemented in Service Robotics by his Master for Performance Monitoring.

A master can only lock or unlock the service robotics.

\section{REVIEW OF LITERATURE}

(Rimmy Chuchra et. al. 2013) This paper discussed about the joint action taken by the humans and robotics for performing any task. Humans and robotics holds master/slave relationship where interface acts as a sandwich between the humans and robotics. The use of interface is to provide communication between human and robotics in natural way where human acts as a master and is responsible for giving instructions to robotics and robotics always acts as a slave that work as per instructions given by their master. The communication flow methodology between human and robotics can be shown in fig.7: [2]

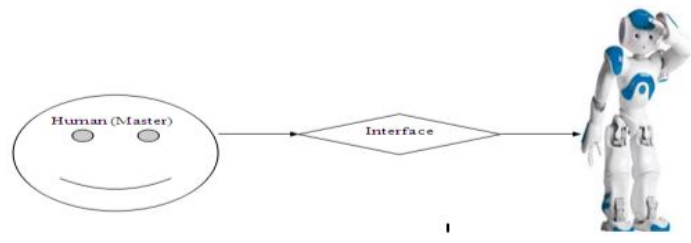

Fig.7: HRI: Shows Master/Slave Relationship.

(Rimmy Chuchra et. al. 2014): Authors proposed a new procedure termed as "Human-robotics Interaction based analysis-Using data mining techniques" that shows how humans and robotics performed any task collectively by utilizing three different data mining techniques viz. classification, regression analysis and time series analysis. This designed methodology worked only with single type of data input format. It must be in discontinuous form (i.e. - in digital form). Theoretical and experimental based analysis investigated in this paper with significant results. [1]

(R.K Seth et. al. 2015): Authors designed a new communication flow methodology that works on two separate types of inputs given by the user viz. analog and digital form. The designed methodology also provides more natural way of communication while utilizing interface. Instructions can be easily managed by robotics given by the master-human. [3]

\section{ROAD MAP OF FPMS}

This roadmap gives an idea how service robotics calculates the performance of employees and is as shown in fig.8:

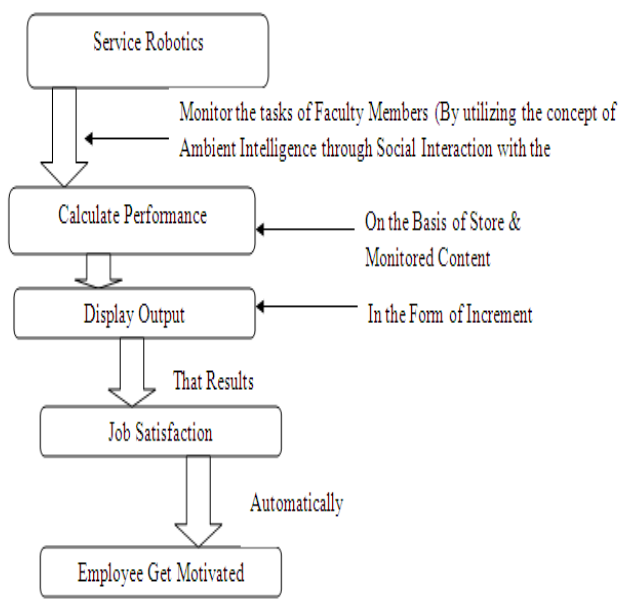

Fig.8: Working of Service Robotics for calculating performance of employees. 


\section{RESEARCH DESIGN}

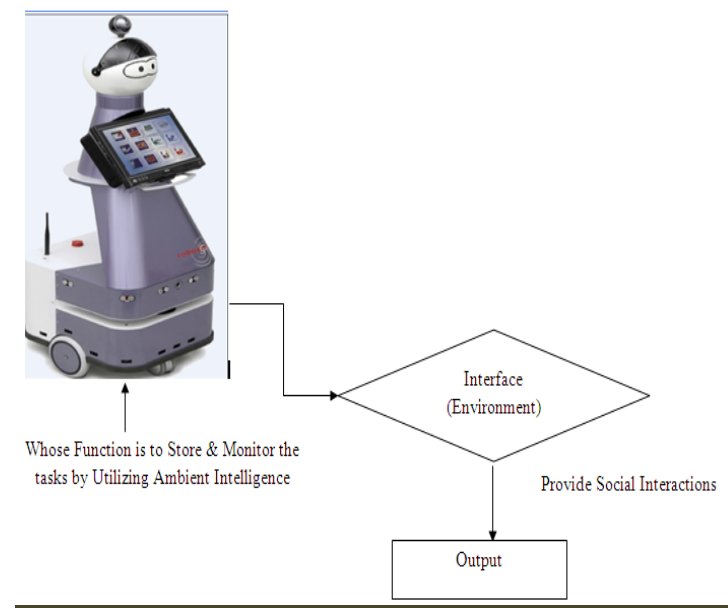

Fig.9: Working of Service Robotics with Environement.

\section{CONCLUSION}

This paper elaborated a variety of parameters for evaluating the efficiency of the faculty members in the institutes based upon the results evaluated by FPMS. The proposed algorithm may be used to improve the work performance at work places. The Ambient Intelligence has a great potential to figure out the different kinds of conflicts at the workplaces and also may be utilized to resolve the issues by providing the solutions using the architecture as designed by the authors. The designed methodology helps to provide a more natural way of interaction between human and service robotics using a simple form of mechanism of commands.

\section{FUTURE SCOPE}

This work will be extended by developing a common tool that helps to calculate the overall performance of faculty and students collectively. And the parameters used during calculating the performance may be used as a combination of reusable components to make the system more cost effective.

\section{REFERENCES}

[1] Rimmy Chuchra \& R.K Seth March-2014. Human robotics interaction based analysis-Using DMT, International Journal of Computer Science and Information Technology.

[2] Rimmy chuchra \& Ramandeep kaur, Feb 2013. Human robotics interaction with data mining techniques", International Journal of Emerging Technology And Advance Engg.

[3] R.K Seth \& Rimmy Chuchra Jan-2015. Synergetic Interaction among Humans and Robotics by Proposing Communication Flow Methodology, International Journal of Computer Applications.

[4] Shoshana L. Hardat \& William J. Rapaport, "Recent and Current artificial intelligence research in the department of computer science", state university of New York.

[5] Vladimir Villarreal, Jesus Fontechna, Ramon Hervas and Jose Bravo,"Ambient Intelligence: Technological solutions for wellness \& supporting to daily activities,"Latin American \& Caribbean Conference, Panama-2012.

[6] Bannie J.Door, Lucian Galescu, Jan 2015.Perera, Kristy Hollingshead-setiz and David Atkinson,'Speech adaption in extended ambient intelligence environments", Proceedings of the annual conference, Austin.

[7] Thomas Fuhrman, Software Engg for ambient intelligent systems, Universidad Karlsruhe.

[8] Yogita Gigras and Kusum gupta,Ambient Intelligence in Ubiquitous Robotics, International Journal of Computer Science \& Information Technology.

[9] Emile-arts and Boris de Ruyter, 2009. New research prospective on ambient intelligence, Journal of ambient intelligence and smart Environment, IOS Press, Philips Research Europe, Netherland.

[10] A.J.N Van Breemen, K.Crucq and B.J.A Krose ${ }^{++, " ~ A ~}$ User Interface Robot for Ambient Intelligence Environment", Philips Research (SWA), Netherland.

[11] Tom Gross, 2010. Towards a new Human-Centered Computing Methodology for Co-operative Ambient Intelligence, Journal Ambient Intel Human Compute.

[12] Andrej-Adnan Ismail, Adina-Magda Florea, 2014. Solving Experiment Reproducibility In Ambient Intelligence.

[13] P.Wolf, A.Schmidd, J.P.Otte, M.Klein, S.Rollwage, B.Konig-Ries, T.Dettoborn and A.Gabdulkhakova, 2010.Openaal the open source middleware for ambientassisted living (AAL).In AALIANCE Conference, Malaga, Spain.

[14] Naci Dai,Wolfgang Thronicke,Alejandra Ruiz Lopez, Felix Cuadrado Latusa,Elmar zeeb,Chri Stoph Fiehe,Anna Litvina,Jan Krueger, Oliver Dohndrof,ISAAC Agudo,et al.Osami,2011. Commons an Open Dynamic Service Platform for Ambient Intelligence. In Emerging Technologies \& Factories Automation (ETFA), IEEE $16^{\text {th }}$ Conference.

[15] www.igi-global.com/book/handbook-research-ambientintelligence-smart/41775.

[16] www.bava.de/en/Topics.FromAtoZ/AmbientIntelligence/ Research map/Project details/Projectdetails.html?

[17] Kristrun gunnarsdottir-cesafen, Luneaster Univ/Michael Arribas-Ayllon-SOCSI, Cardiff Univ, Ambient intelligence:-A Narrative in search of users.

[18] Carlos Ramos, Juan Carles Augusto, Daniel Shapiro, Ambient Intelligence", GECAD-Institute of Engg. Polytechnic of Porto, Portugal, University of Ulster, UK, Applied Reactivity Inc, USA.

[19] http://www.vision mobile.com/blog/2012/101ambientintelligence-how-well-does-your-phone-know-you/.

[20] epia2015.dei.uc.pt/ambient-intelligence-and-affectiveenvironment/.

[21] Roberto Casas, Ruben Blasco Marin, Alexia Robinet and Armando Roy Delgado, User Modelling in Ambient Intelligence for elderly \& disabled people, Centre for applied Internet Research (CACR), University of wales, UK.

[22] Juan Carlos Augus to Paul Mcuellagh, Ambient Intelligence: Concepts \& Applications, School of CS \& Maths, and University of ulster at Jordan town. 
[23] Linda little, Briggs, Using Ambient Intelligent Systems For exchanging health Information, PACT Lab, North Umbria University, UK.

[24] www.seminarsonly.com/computer\%20science/ambientintelligence.php.

[25] Matt Duckhan and Rohan Bennett, 2010.Ambient Spatial Intelligence For Sustainable Cities, Australia, University of Melbourne, Parkville, Victoria.

[26] http://www.reuters.com/article/2015/02/26/researchidusn Bw265933a+100+BSW20150226.

[27] www.newyorker.com/magzine/2015/01/19/know-feel.

[28] www.termpaperwarehouse.com/essay-on/ambient intelligence/302220.

[29] www.supsi.ch/isin-en/ricerca-servizi/Ambient intelligence.html.

[30] Alves Leno, Jorge and Salem Bernard, 2010. Responsive Environments: "User Experiences for ambient intelligence, Journal of Ambient Intelligence \& smart Environment.

[31] Fariba Sadri, Artificial Societies for Ambient Intelligence, International journal of autonomous \& adaptive Communication systems, UK.
[32] Werner Weber, Ambient Intelligence Industrial research on a visionary Concept, Infineon Technologies, Labs for Emerging Technologies.

[33] Web.fru.eu/en/Research-Programmes/Funding-by-calltype/Projects/Convivialty-and-Privacy-in-AmbientIntelligence-Systems-COAPIns.

[34] Galati's George,2013.Multimodal Interaction in Ambient Intelligence environments using Speech, Localization and Robotics, National Centre for scientific research,Democritus,Institute of Informatics and telecommunications.

[35] www.abc.net.ac/catapult/indepth/s240082.htm.

[36] ercim-news.ercim.eu/en67/special-theme-embedded intelligence/a-european-ambient-intelligence-researchfacility-at-ics-forth.

[37] Alessandro Sajjiotti, Mathias Bronxville,2005.PEIS ecologies: Ambient Intelligence->meets Autonomous Robotics, ACM, New York, UK.

[38] Albrecht Schmidt, 2005.Interactive Context Aware Systems Interacting with Ambient Intelligence, IOS Press.

[39] www.gifer.com/upp/mdgmtn/Custom/Pub/Content,rid,10 3816/Long,2/ticket.g-u-e-s-t/u/Beautiful-and-intelligentworking-world-An-Exhibition-on-ambientintelligence.html. 